\title{
MECANISMOS FISIOPATOLÓGICOS DA NOCICEPÇÃO E BASES DA ANALGESIA PERIOPERATÓRIA EM PEQUENOS ANIMAIS
}

\author{
José Edgard de Oliveira ALVES ${ }^{* 1}$, Máyra Dias SILVEIRA ${ }^{1}$, Evelyn Mayara Perrut VIEIRA ${ }^{2}$ \& Leonardo \\ Waldstein de Moura VIDAL ${ }^{3}$
}

1 Universidade Federal Rural do Rio de Janeiro, Seropédica, Rio de Janeiro, Brasil.

2 Universidade Severino Sombra, Vassouras, Rio de Janeiro, Brasil.

3 Universidade Estadual do Norte Fluminense - Darcy Ribeiro, Campos dos Goytacazes, Rio de Janeiro, Brasil.

*Autor para correspondência: edgardoliveiraalves@hotmail.com

DOI: http://dx.doi.org/10.18571/acbm.122

\section{RESUMO}

A nocicepção é o fenômeno pelo qual ocorre a codificação e o processamento dos estímulos ambientais físicos e químicos ou patológicos que resultam na dor, através de uma cascata complexa de eventos da periferia até as estruturas superiores do sistema nervoso central. O reconhecimento e a avaliação da dor são etapas fundamentais para o sucesso em seu tratamento e devem ser baseados em indicadores fisiológicos, biomarcadores específicos e de parâmetros comportamentais. A analgesia preemptiva, a analgesia multimodal e o advento de novos fármacos trouxeram grandes avanços no controle da dor perioperatória, reduzindo ou evitando a sensibilização neuronal decorrente dos estímulos nociceptivos cirúrgicos, promovendo melhor analgesia e conforto pós-operatórios, resultando em um menor requerimento de fármacos analgésicos no pós-cirúrgico e em uma recuperação mais acelerada. O presente artigo teve como objetivo abordar os aspectos atuais da nocicepção e do controle da dor perioperatória em pequenos animais.

Palavras-chave: Dor; Analgesia multimodal; Anestesia.

\begin{abstract}
Nociception is the phenomenon whereby occur the encoding and processing of physical and chemical environmental or pathological stimulus that results pain, through a complex cascade of events from peripheral to high central nervous system structures. The recognition and assessment of pain are fundamental stages to the success in its treatment and should be based in physiological indicators, specific biomarkers and behavioral parameters. The preemptive analgesia, multimodal analgesia and the advent of novel drugs brought great advances in perioperative pain management, reducing or preventing neural sensitization due surgical nociceptive stimulus, promoting better analgesia and postoperative comfort, resulting in a lower requirement of analgesic drugs postsurgical and promoting a faster recuperation. This article had aim approaches current aspects of nociception and perioperative pain management in small animals.
\end{abstract}

Keywords: Pain; Multimodal analgesia; Anesthesia.

\section{Introdução}

Os sistemas sensoriais têm o importante papel de informar o sistema nervoso central (SNC) sobre as condições do ambiente externo e o estado do meio interno do organismo. A dor é um tipo de percepção e, como tal, é parte de um sistema complexo, o sistema nociceptivo, que compõe um conjunto global de mecanismos responsáveis pelo controle da homeostase. Neste contexto, a dor constitui um sinal de alerta, cuja função é ajudar a proteger o organismo, desencadeando reações 
que induzem comportamentos específicos com o objetivo de evitar ou reduzir os estímulos que estejam causando-a, tendo como resultado o encerramento ou limitação dos danos consequentes (LE BARS et al., 2001).

Com os avanços nos conhecimentos referentes aos conceitos relacionados ao bem-estar animal, enfatizou-se a importância da prevenção e do tratamento da dor nos pacientes veterinários (LIMA SILVA et al., 2011). Portanto, a dor deve ser abordada como uma responsabilidade ética do médico veterinário, uma vez que está diretamente ligada ao bem-estar (BROOM; MOLENTO, 2004). Além disso, a dor frequentemente resulta em um tempo de hospitalização mais prolongado e aumenta o potencial para desenvolvimento de problemas secundários a ela (DYSON, 2008).

Diante dos progressos recentes na ciência do bem-estar e no desenvolvimento de novos fármacos e técnicas analgésicas, o presente estudo teve como objetivo abordar os aspectos atuais da nocicepção e do controle da dor perioperatória em pequenos animais.

\section{Nocicepção e analgesia}

\subsection{Fisiolopatogia da dor}

O processo neural de codificação e processamento do estímulo nocivo é chamado de nocicepção (NAIDU; PHAM, 2015). A primeira etapa da sequência de eventos que origina o fenômeno sensitivo-doloroso é a transformação dos estímulos ambientais físicos ou químicos em potenciais de ação, que, das fibras nervosas periféricas, são transferidos para o SNC (TEIXEIRA, 2001). Essa transformação é chamada de transdução e ocorre através dos nociceptores localizados em tecidos superficiais, profundos e vísceras, que se apresentam como terminações nervosas livres. Quando um estímulo nocivo é aplicado ao organismo, os nociceptores são ativados e uma informação de agressão é encaminhada ao SNC (GOZANNI, 2003).

A via aferente primária que conduz a informação a partir destas terminações nervosas consiste em dois principais tipos de inervação: Fibras C não mielinizadas e fibras A-delta mielinizadas (McKUNE et al., 2015; NAIDU; PHAM, 2015). De acordo com os estímulos que os acionam, podem ser também designados como mecanonociceptores, termonociceptores e nociceptores polimodais inespecíficos (GOZANNI, 2003; TEIXEIRA, 2001).

As fibras A-delta são responsáveis pela primeira fase da dor, caracterizada pela velocidade de transmissão e intensidade, e são sensíveis a estímulos mecânicos intensos. As fibras C produzem uma segunda fase de dor que se descreve como difusa e persistente e formam, na periferia, receptores de alto limiar para estímulos mecânicos e térmicos (KLAUMANN et al., 2008). Após lesão tecidual, fibras A-beta, normalmente não associadas a processos nociceptivos, mas apenas à estímulos inócuos, também podem sofrer alterações celulares e, após a sensibilização na periferia, transmitir a informação nociceptiva (MATHEWS et al., 2014).

Diversos mediadores algogênicos estão envolvidos no processo de sensibilização periférica. Após a ocorrência de um dano tissular, as células lesadas extravasam enzimas que, no meio extracelular, ciclizam ácidos graxos de cadeia longa e agem sobre os cininogênios, formando as cininas, especialmente a bradicinina, uma substância algógena e vasoativa. Sob ação da fosfolipase A2, ocorre liberação de ácido aracdônico a partir da membrana celular, iniciando o envolvimento de outros mediadores inflamatórios. A biossíntese de prostaglandinas promove redução do limiar de excitabilidade dos nociceptores, fazendo, então, com que estímulos menos intensos sejam capazes de ativá-los (GOZANNI, 2003).

Além das substâncias já citadas, outros inúmeros mediadores participam do processo de sensibilização periférica. Dentre eles, de caráter excitatório, encontram-se o hidrogênio, potássio, histamina, citocinas como interleucinas e fator de necrose tumoral alfa, substância P, ATP, glutamato e aspartato. Por outro lado, as beta-endorfinas, somatostatina, acetilcolina, encefalinas, glicina, GABA, norepinefrina e a serotonina apresentam um papel inibitório no processo de 


\section{ACTA \\ Biomedica Brasiliensia}

ISSN: 2236-0867

nocicepção (NAIDU; PHAM, 2015). O resultado da sensibilização periférica é o estabelecimento de hiperalgesia, isto é, quando um estímulo normalmente doloroso provoca uma resposta exacerbada, e alodinia, quando um estímulo normalmente inócuo resulta em dor (HELLYER et al., 2007).

A ativação de receptores específicos e canais iônicos, presentes na maior parte dos tecidos e órgãos, nas terminações nervosas periféricas por estímulos químicos, mecânicos ou térmicos inicia a propagação de um potencial de ação que percorrerá todo o axônio das fibras primárias aferentes até os sítios de sinapse na medula espinhal. Isto desencadeia a liberação de neurotransmissores, incluindo glutamato e substância $\mathrm{P}$, que irão ativar neurônios situados na medula espinhal (McKUNE et al., 2015).

A substância cinzenta da medula espinhal é dividida em dez lâminas, de acordo com suas características citoarquitetônicas. O corno dorsal é constituído pelas lâminas I a VI, sendo as lâminas VII a IX constituintes da zona intermediária e corno ventral e a lâmina $\mathrm{X}$ a zona que contorna o canal central (CASTRO LOPEZ, 2003). Os neurônios nociceptivos do corno dorsal da medula espinhal estão localizados nas lâminas mais superficiais e a maior parte deles recebe conexões diretas de fibras A-delta e fibras C. Muitos dos neurônios da lâmina I, também conhecida como zona marginal, respondem exclusivamente a estímulos nociceptivos e projetam-se para centros superiores. Alguns neurônios desta lâmina respondem de maneira gradativa a estímulos mecânicos nocivos e inócuos, sendo estes designados de neurônios de faixa dinâmica ampla ou WDR - do inglês wide dynamic range. A lâmina II ou substância gelatinosa é formada predominantemente por interneurônios inibitórios e excitatórios (KLAUMANN et al., 2008).

A população de neurônios de segunda ordem pode ser dividida em três grupos: (1) interneurônios, que podem apresentar função excitatória ou inibitória e têm papel fundamental na modulação local da transmissão nociceptiva; (2) neurônios proprioespinhais, que apresentam envolvimento com a atividade reflexa; e (3) neurônios de projeção ou WDR, que participam da transmissão da informação nociceptiva através da medula espinhal até os centros supraespinhais (KLAUMANN et al., 2008; CASTRO LOPEZ, 2003). Os três componentes são interativos e essenciais para o processamento da informação nociceptiva, possibilitando a geração de uma resposta apropriada e organizada (KLAUMANN et al., 2008). Estes neurônios podem ser também classificados funcionalmente como: não-nociceptivos - isto é, aqueles que respondem à estímulos inócuos -, nociceptivos específicos - neurônios que respondem exclusivamente à estímulos nocivos -, e, finalmente, os neurônios nociceptivos de largo espectro dinâmico ou WDR - cuja resposta se dá tanto a estímulos inócuos quanto a estímulos nóxicos, variando em suas proporções de acordo com a intensidade do estímulo (CASTRO LOPES, 2003).

Sabe-se que diversos receptores participam da transmissão nociceptiva na medula espinhal. Em geral, são observados em posição pré-sinaptica receptores opióides mu/delta e kappa, receptores GABA b, alfa2-adrenérgicos, neurocinina 1 e serotoninérgicos (5HT2). Em contraste, os sítios pós-sinápticos são dotados de receptores GABA a e b, AMPA, NMDA, mu, mu/delta, alfa2-adrenérgicos, serotoninérgicos (5HT1b) e adenosina. A transmissão excitatória na medula espinhal é feita principalmente pelo glutamato e secundariamente pelo aspartato e em muitas sinapses a liberação de glutamato é conjunta à liberação de substância $\mathrm{P}$ e neurocininas, que são designadas como neuromoduladores (GOZANNI, 2003).

A modulação inibitória também ocorre no corno dorsal da medula e pode ser mediada por estímulos periféricos não nociceptivos, por interneurônios inibitórios GABAérgicos e glicinérgicos locais e por projeções descendentes bulboespinhais. Estes mecanismos inibitórios são ativados de maneira endógena com o objetivo de reduzir as respostas excitatórias à atividade prolongada de fibras $\mathrm{C}$ através de neurotransmissores como endorfinas, encefalinas, noradrenalina e serotonina. Por este motivo são também alvo de ação de diversos agentes analgésicos exógenos (MACINTYRE et al., 2010). Em outras palavras, a modulação é um fenômeno complexo que modifica a qualidade, a severidade e a duração da percepção dolorosa (NAIDU; PHAM, 2015). 
As fibras destes nociceptores de segunda ordem se projetam pela medula espinhal e alcançam o tálamo através do trato espinotalâmico, bem como outras regiões superiores do SNC são alcançadas através dos tratos espinorreticular, espinomesencefálico, espinocervical e espinohipotalâmico. A partir deste ponto, o neurônio de terceira ordem finalmente chega ao córtex cerebral, onde ocorre a percepção da dor (NAIDU; PHAM, 2015; KLAUMANN et al., 2008). Este complexo sistema de vias diretas e indiretas de transmissão das informações nociceptivas inerva o tálamo, o mesencéfalo, o sistema límbico e a formação reticular. Estes centros nervosos são responsáveis pela localização da dor, sua intensidade, bem como os aspectos afetivos e cognitivos (KLAUMANN et al., 2008).

Este modelo de ativação produz uma resposta difusa a partir de feedbacks positivos e negativos, cuja informação relativa ao estímulo nóxico pode ser amplificada ou diminuída. Axônios serotoninérgicos e noradrenérgicos descendentes oriundos de sinapses cerebrais com interneurônios na medula espinhal modificam suas funções e, em animais sadios, são considerados responsáveis pela analgesia induzida por estresse. Em condições alteradas pela dor, este efeito pode ser atenuado e então pode haver uma desinibição local com o potencial de aumentar a percepção da dor (McKUNE et al., 2015).

Um sistema complexo de neurotransmissores e receptores é responsável pela transmissão em neurônios nociceptivos ou em vias modulatórias a nível talâmico e cortical. Acredita-se que o glutamato e o aspartato constituam os principais mediadores excitatórios envolvidos na transmissão e processamento no sistema talamocortical. Os aminoácidos inibitórios (GABA e glicina), as monoaminas (noradrenalina, serotonina e dopamina), a acetilcolina e histamina também apresentam envolvimento no processo de excitabilidade talamocortical, além da ciclooxigenase 2 (COX-2), expressada pelo córtex cerebral, sugerindo um provável papel de prostaglandinas na modulação cortical (KLAUMANN et al., 2008). Uma vez desencadeada, a sensibilização central persiste por período prolongado, mesmo com a retirada do estímulo inicial. A principal implicação clínica decorrente deste complexo mecanismo fisiopatológico é o fato de ser mais vantajoso prevenir o desenvolvimento de sensibilização central do que tratar a dor após o seu estabelecimento (GOZANNI, 2003).

\subsection{Tipos de dor}

Existem diferentes formas de descrever a dor. Do ponto de vista temporal, a dor pode ser classificada como aguda ou crônica. Todavia a diferenciação entre estes conceitos pode apresentar grande subjetividade (McKUNE et al., 2015). A dor aguda é definida como dor de início recente e de duração provavelmente limitada. Usualmente tem um ponto de identificação temporal e correlação causal com uma determinada lesão ou doença (MACINTYRE et al., 2010). Em contraste, a dor crônica persiste além do período esperado para a cura de uma doença ou injúria, podendo manifestar-se espontaneamente ou ser provocada por vários estímulos exógenos, com resposta tipicamente exagerada em duração, amplitude ou ambas (KLAUMANN et al., 2008), geralmente associada a afecções inflamatórias crônicas ou doenças degenerativas ou, ainda, como consequência de danos ou lesões neurais (McKUNE et al., 2015).

Apesar de tradicionalmente a dor ter sido classificada com base em sua duração como aguda ou crônica, uma definição mais recente se refere à dor como adaptativa ou não-adaptativa. A primeira apresenta-se como uma reação normal a uma lesão tecidual, incluindo a dor inflamatória. A inflamação é o maior componente de diversas condições ligadas a dor, como a dor aguda póscirúrgica ou traumática, por exemplo, e algumas situações que envolvem a dor crônica, como na osteoartrite. Os mediadores inflamatórios sensibilizam as vias neurais, aumentando a percepção da dor. Caso a dor adaptativa não seja adequadamente tratada, ocorrem modificações a nível espinhal e supraespinhal que determinam a nomenclatura não-adaptativa. Exemplos de dor nãoadaptativa incluem a dor neuropática, quando ocorre uma injúria ao sistema nervoso, ou por 
alterações no processamento e na percepção de um estímulo nóxico normal (HELLYER et al., 2007).

De maneira similar, outras literaturas referem-se à dor como fisiológica ou patológica. Em síntese, a dor fisiológica - ou nociceptiva - é tipicamente descrita como um evento agudo e transitório envolvendo um estímulo nocivo, com o objetivo de manter a homeostase e evitar ou reduzir os danos decorrentes de uma lesão tissular. Por outro lado, a dor patológica envolve desconforto e sensibilidade anormal na sintomatologia do paciente acometido, podendo ser classificada como dor inflamatória - que pode envolver estruturas somáticas ou viscerais - ou neuropática, quando envolve lesões do sistema nervoso (KLAUMANN et al., 2008). A dor oncológica pode apresentar características tanto inflamatórias quanto neuropáticas (McKUNE et al., 2015).

\subsection{Reconhecimento e avaliação da dor}

Qualquer lesão tissular, incluindo aquelas decorrentes de procedimentos cirúrgicos eletivos, podem causar dor. O estresse orgânico produzido como resposta ao fenômeno sensitivo-doloroso, mediado pelo sistema neuroendócrino, é uma das consequências negativas da dor (HELLYER et al., 2007). Pacientes sob anestesia durante procedimentos cirúrgicos se apresentam inconscientes e incapazes de interpretar a dor, mas isto não necessariamente irá atenuar o processamento da informação nociceptiva decorrente do estresse cirúrgico e a percepção alterada da dor após o despertar. Este fato enfatiza a importância da analgesia preemptiva (McKUNE et al., 2015), haja vista que a prevenção ou manejo inadequados da dor podem levar à magnificação da percepção dolorosa e prolongar a duração desta condição (HELLYER et al., 2007).

Em animais anestesiados, a avaliação do fenômeno sensitivo-doloroso é mais difícil e restringe-se basicamente à mensuração de indicadores fisiológicos, tais como o aumento da frequência cardíaca com ou sem a presença de arritmias, aumento da frequência respiratória e elevação da pressão arterial sistêmica (McKUNE et al., 2015; PERKOWSKI, 2015), todavia estes parâmetros não são indicadores totalmente confiáveis por sofrerem influência de outros fatores, especialmente de fármacos anestésicos (MATHEWS et al., 2014), e devem ser avaliados de acordo com o contexto clínico em que se apresentam.

Em animais conscientes, a avaliação primária da dor aguda é baseada em sinais comportamentais característicos e em parâmetros fisiológicos. As concentrações plasmáticas de biomarcadores como cortisol, beta-endorfinas e proteínas de fase aguda tem sido mensuradas como indicadores de dor e apresentado correlação com os indicadores comportamentais (McKUNE et al., 2015).

Os indicadores comportamentais mais comuns para avaliação da dor incluem a redução das caminhadas e do apetite, letargia e o ato de autolimpeza irregular em gatos. Além disso, outros sinais comportamentais permitem avaliar a ocorrência e o grau de dor nos pacientes veterinários, tais como o desenvolvimento de comportamentos anormais como vocalização, agressão, postura ou expressão facial alterada, inquietação ou o ato de se esconder - sobretudo em gatos (HELLYER et al., 2007).

Existem diversos instrumentos para avaliação da dor em medicina veterinária. As escalas unidimensionais, como a escala de avaliação numérica, escala descritiva simples, escala analógica visual, apesar de altamente subjetivas, são métodos atualmente aceitos para avaliação. As escalas compostas apresentam uma avaliação mais complexa da condição dos pacientes, considerando não apenas a intensidade da dor, como ocorre nas escalas unidimensionais, como também dados fisiológicos e respostas comportamentais, permitindo maior acurácia na avaliação do quadro. Dentre elas, destacam-se a escala de dor da Universidade do Colorado, escala de dor da Universidade de Melbourne, e a escala composta de Glasgow. A escala multidimensional da 
UNESP/Botucatu é um instrumento validado para avaliação da dor em gatos (MATHEWS et al., 2014).

\subsection{Controle da dor perioperatória em pequenos animais}

O avanço recente da ciência do bem-estar animal aguçou o senso crítico da necessidade de prevenção e tratamento adequado da dor nos animais. Nesse contexto, reforça-se a importância do conhecimento médico veterinário sobre fármacos e técnicas utilizados para o controle da dor (LIMA SILVA et al., 2011). Dificuldades no diagnóstico e na avaliação precisa da dor representam desafios para o médico veterinário e o eventual desconhecimento acerca dos fármacos analgésicos disponíveis e das técnicas que comumente contribuem para o controle da dor perioperatória de pacientes veterinários dificultam o manejo adequado desta condição, que tem importância direta sobre o bem-estar e a recuperação do paciente (BERRY, 2015).

Uma grande variedade de técnicas tem sido amplamente desenvolvidas por extrapolação de experiências clínicas em pacientes humanos e baseadas em aspectos comparativos da fisiopatologia da dor em humanos e animais (FLECKNELL, 2008). Fármacos, técnicas ou métodos usados para prevenir ou controlar a dor devem, ainda, ser adaptados individualmente para cada paciente, mesmo aqueles de uma mesma espécie, uma vez que a dor é uma experiência particular e individual, baseando-se nos graus de trauma tecidual, características comportamentais do indivíduo, graus de dor avaliados e o estado de saúde do paciente (ANTUNES et al., 2008).

Atualmente, opióides e anti-inflamatórios não esteroidais (AINEs) consistem nas duas mais importantes classes de medicamentos para o tratamento da dor aguda (HANSEN, 2008). A analgesia balanceada ou multimodal é obtida através da administração de duas ou mais classes de fármacos ou técnicas analgésicas, que podem incluir AINEs, opióides, agonistas alfa2adrenérgicos, anestésicos locais e antidepressivos tricíclicos, entre outros, que apresentam efeitos analgésicos aditivos ou sinérgicos quando coadministrados (LIMA SILVA et al., 2011).

\subsubsection{Analgesia preemptiva e controle multimodal da dor}

O termo analgesia preemptiva conceitua uma forma de analgesia empregada antes do estímulo doloroso ser gerado, prevenindo ou diminuindo a dor subsequente, e potencialmente resultando em menor dor pós-operatória (BECKMAN, 2013; GRAPE; TRAMER, 2007; VALLEJO et al., 2006; GARCIA et al., 2001), baseando-se na tese de que prevenir o estabelecimento da sensibilização central é mais vantajoso do que tratar a dor já estabelecida. Em outras palavras, é uma estratégia que visa obter analgesia pós-operatória eficiente, com redução da memória da dor, atenuando a sensibilização central induzida pelos estímulos nociceptivos inerentes ao procedimento cirúrgico (LIMA SILVA et al., 2011).

O controle da dor iniciado precocemente com a administração preemptiva de opióides ou a realização de bloqueios anestésicos regionais contribui para reduzir ou dispensar a necessidade de resgate analgésico no período pós-operatório imediato (FREITAS et al., 2016; BECKMAN, 2013). Em adição, o emprego da analgesia preemptiva nos protocolos anestésicos diminui significativamente o requerimento de fármacos para a indução e manutenção e permite que o animal seja mantido em um plano anestésico ideal, minimizando o grau de depressão cardiorrespiratória induzida pelos anestésicos gerais (LIMA SILVA et al., 2011).

O controle multimodal da dor ou analgesia balanceada é o tratamento da dor cuja abordagem envolve a combinação de diferentes classes de analgésicos ou técnicas, os quais permitem otimizar o manejo da dor, enquanto limitam a ocorrência de efeitos adversos (MATHEWS et al., 2014; LEE et al., 2013; FANTONI; MARTINS, 2012). O emprego da analgesia multimodal permite promover analgesia adicional ou sinergismo entre os fármacos utilizados, cujos alvos de ação sejam diferentes sítios ao longo da via nociceptiva. Além disso, estas associações possibilitam a 


\section{Biomedica Brasiliensia}

ISSN: $2236-0867$

aplicação de doses mais baixas de cada fármaco individualmente, reduzindo a incidência de efeitos adversos (GRUBB, 2010).

Apesar de se mostrar uma estratégia simples em sua essência, um manejo multimodal efetivo deve considerar uma abordagem racional da nocicepção, baseada na compreensão dos mecanismos fisiopatológicos, neuroendócrinos e bioquímicos envolvidos, tendo em vista as intervenções farmacológicas ou técnicas apropriadas para sanar as necessidades do paciente (LAMONT, 2008a). Esta combinação de fármacos deve ser utilizada sempre que possível, pois previne e trata a sensibilização central, responsável pelo desenvolvimento da dor persistente e crônica (FANTONI; MARTINS, 2012).

Os medicamentos mais comumente utilizados para compor os protocolos de analgesia multimodal incluem os opióides, AINEs, anestésicos locais, antagonistas NMDA e agonistas alfa2-adrenérgicos (MATHEWS et al., 2014), além de outros fármacos adjuvantes, tais como os anticonvulsivantes, a exemplo da gabapentina, antidepressivos tricíclicos, como a amitriptilina e a imipramina, inibidores da receptação de monoaminas, como a amantadina, por exemplo, entre outros (BECKMAN, 2013; MACINTYRE et al., 2010; LAMONT, 2008b).

Tabela 1: Fármacos e doses comumente empregados para controle da dor em cães e gatos.

\begin{tabular}{|c|c|c|}
\hline Fármaco & Caninos & Felinos \\
\hline \multicolumn{3}{|l|}{ Opióides } \\
\hline Tramadol* & $4-6$ mg/kg VO BID ou TID & 2 - 4 mg/kg VO BID \\
\hline Morfina & $0,3-1 \mathrm{mg} / \mathrm{kg}$ IM a cada 2-4 horas & $0,2-0,4 \mathrm{mg} / \mathrm{kg}$ IM a cada $2-4$ horas \\
\hline Meperidina & $3-5 \mathrm{mg} / \mathrm{kg} \mathrm{IM}$ a cada $1-2$ horas & $3-10 \mathrm{mg} / \mathrm{kg}$ IM a cada $1-2$ horas \\
\hline Metadona & 0,5 - $1 \mathrm{mg} / \mathrm{kg}$ IM, IV a cada 3-4 horas & $0,3-0,6 \mathrm{mg} / \mathrm{kg}$ IM a cada 4 horas \\
\hline Butorfanol & $0,2-0,4 \mathrm{mg} / \mathrm{kg} \mathrm{IM}, \mathrm{IV}$ a cada $1-2$ horas & $0,2-0,4 \mathrm{mg} / \mathrm{kg}$ IM, IV a cada $1-2$ horas \\
\hline \multicolumn{3}{|l|}{ AINEs } \\
\hline Cetoprofeno** & $1-2 \mathrm{mg} / \mathrm{kg}$ VO, IV, SC, IM SID & $1 \mathrm{mg} / \mathrm{kg}$ VO SID \\
\hline Carprofeno & $2,2-4,4$ m/kg VO SID ou BID & 2 - 4 mg/kg IV, SC (dose única) \\
\hline Meloxicam** & $0,1-0,2 \mathrm{mg} / \mathrm{kg} \mathrm{VO}, \mathrm{IV}, \mathrm{SC}$ SID & $0,05-0,2 \mathrm{mg} / \mathrm{kg}$ IV, $\mathrm{SC}$ SID \\
\hline Firocoxibe & $5 \mathrm{mg} / \mathrm{kg}$ VO SID & Não indicado \\
\hline \multicolumn{3}{|l|}{ Adjuvantes } \\
\hline Amantadina & $3-5 \mathrm{mg} / \mathrm{kg}$ VO SID & $3-5 \mathrm{mg} / \mathrm{kg}$ VO SID \\
\hline Gabapentina & $3-10 \mathrm{mg} / \mathrm{kg}$ VO BID ou TID & 3 - $10 \mathrm{mg} / \mathrm{kg}$ VO BID ou TID \\
\hline Amitriptilina & $1-2 \mathrm{mg} / \mathrm{kg}$ VO SID ou BID & $2,5-12,5 \mathrm{mg} / \mathrm{kg}$ VO SID \\
\hline Imipramina & $0,5-1 \mathrm{mg} / \mathrm{kg}$ VO TID & $2,5-5 \mathrm{mg} / \mathrm{kg}$ VO BID \\
\hline
\end{tabular}

Os agonistas opióides atuam nos receptores opioidérgicos no SNC e periférico, inibindo a liberação de neurotransmissores excitatórios nas fibras aferentes do corno dorsal da medula espinhal, através da inibição da transmissão sináptica do estímulo nociceptivo. Sua ação póssináptica aumenta o efluxo de $\mathrm{K}+$, causando hiperpolarização neuronal dos neurônios de projeção na medula espinhal e inibindo as vias ascendentes da nocicepção (MATHEWS et al., 2014).

A escolha do opióide a ser utilizado deve basear-se na condição clínica do paciente, tipo de procedimento e na expectativa do grau e da duração da dor. Comumente os agonistas mu puros, como morfina e fentanil, por exemplo, são empregados para controle da dor moderada a severa (BERRY, 2015), enquanto os agonistas parciais são menos efetivos, porém ainda assim exercem 
significante analgesia, sendo boas alternativas para o tratamento da dor moderada. Agonistasantagonistas, como o butorfanol, são usualmente recomendados para pacientes ou procedimentos associados a um grau de dor suave a moderada (BECKMAN, 2013). O tramadol, apesar de ser um agonista fraco do receptor opióide mu, possui um mecanismo de ação misto, sendo também um inibidor da recaptação de serotonina e norepinefrina, geralmente usado em associação com AINEs ou opióides para o manejo da dor crônica e pós-operatória em cães e gatos (MATHEWS et al., 2014; HELLYER et al., 2007).

Os anestésicos locais, classe farmacológica que contempla a lidocaína, bupivacaína e outros fármacos, são clássicos bloqueadores reversíveis dos canais de sódio, que atuam impedindo a condução do impulso nociceptivo através da via aferente da dor (LAMONT, 2008a). O uso de anestésicos locais em bloqueios locorregionais promove a atenuação ou eliminação da sinalização sensorial aferente, resultando em uma redução significante do requerimento de fármacos para manutenção anestésica (BECKMAN, 2013). A administração sistêmica de lidocaína promove redução da concentração alveolar mínima (CAM) dos anestésicos halogenados em diversas espécies, sugerindo um possível papel deste fármaco na modulação da dor, além de reduzir a dor pós-operatória e facilitar a recuperação do paciente (McKUNE et al., 2015; ELVIR-LAZO, WHITE, 2010).

Os AINEs são uma classe de fármacos que compartilham efeitos terapêuticos antiinflamatórios, analgésicos e antipiréticos. São os analgésicos mais comumente usados na medicina veterinária em função de sua efetividade tanto para dor aguda quanto crônica (ALLWEILER, 2016). Estes fármacos atuam inibindo a ação da enzima ciclooxigenase (COX) sobre o ácido aracdônico, reduzindo a formação de prostaglandinas (MATHEWS et al., 2014), substâncias próinflamatórias liberadas das células após injúria tecidual, tendo papel fundamental na perpetuação da inflamação e sensibilização dos nociceptores (BECKMAN, 2013).

Os agonistas alfa2-adrenérgicos possuem propriedades sedativas, analgésicas e miorrelaxantes (ALLWEILER, 2016). O uso desta classe de fármacos como adjuvantes analgésicos têm ganhado interesse com o advento da dexmedetomidina (YOUNG; BUVANENDRAN, 2012). Em geral, são empregados para sedação de procedimentos não invasivos e como parte de protocolos de neuroleptoanalgesia e analgesia balanceada, sendo normalmente reservados a pacientes saudáveis (MATHEWS et al., 2014).

Por eliminar a ocorrência de picos e quedas na concentração plasmática que acontecem com as técnicas de bolus ou bolus intermitentes, a infusão contínua intravenosa de analgésicos resulta em uma melhor qualidade de efeito e reduz a dose total fornecida de um determinado medicamento (WHITTEM et al., 2015). Os analgésicos mais utilizados em infusão contínua são fentanil, morfina, lidocaína, cetamina, dexmedetomidina e associações destes, como morfina-cetaminalidocaína (MLK) e fentanil-lidocaína-cetamina (FLK).

Essas associações podem ser mantidas no paciente até que o estímulo doloroso seja interrompido, sendo assim utilizadas por longos períodos, desde que se tenha uma monitoração diária dos gases sanguíneos e da pressão arterial, pois seu uso prolongado pode predispor depressão respiratória e bradicardia com baixo débito cardíaco e hipotensão arterial (FANTONI; MARTINS, 2012). Portanto, salienta-se que a associação farmacológica não está isenta de produzir riscos para o paciente. A associação de vários fármacos pode introduzir uma variável imprevisível, que é o efeito de um agente sobre o efeito ou a concentração dos demais. Essa interação pode resultar em efeitos inesperados, bem como ser fonte de morbidade (BELMONTE et al., 2013). Além disso, esses fármacos podem apresentar efeito cumulativo, sobretudo após muitas horas de infusão, fato mais observado nas associações que contenham fármacos caráter altamente lipossolúvel (FANTONI; MARTINS, 2012). 
Tabela 2: Fármacos comumente usados para infusão contínua intravenosa em pequenos animais.

\begin{tabular}{lccc}
\hline \multicolumn{1}{c}{ Fármaco } & Classe & Dose de carga $(\mathbf{I V})$ & Infusão Contínua \\
\hline Morfina & Opióide & $0,1-0,3 \mathrm{mg} / \mathrm{kg}($ lento $)$ & $0,1-0,3 \mathrm{mg} / \mathrm{kg} / \mathrm{h}$ \\
Fentanil & Opióide & $2-5 \mathrm{mcg} / \mathrm{kg}$ & $4-10 \mathrm{mg} / \mathrm{kg} / \mathrm{h}$ \\
Remifentanil & Opióide & $3 \mathrm{mcg} / \mathrm{kg}$ & $6-18 \mathrm{mcg} / \mathrm{kg} / \mathrm{h}$ \\
Lidocaína* & Anestésico Local & $1-2 \mathrm{mg} / \mathrm{kg}(\mathrm{lento})$ & $2-3 \mathrm{mg} / \mathrm{kg} / \mathrm{h}$ \\
Cetamina & Antagonista NMDA & $0,2-2 \mathrm{mg} / \mathrm{kg}$ & $0,2-2 \mathrm{mg} / \mathrm{kg} / \mathrm{h}$ \\
Dexmedetomidina & Alfa 2 -Agonista & $1 \mathrm{mcg} / \mathrm{kg}$ & $0,5-3 \mathrm{mcg} / \mathrm{kg} / \mathrm{h}$ \\
Medetomidina & Alfa 2 -Agonista & $1 \mathrm{mcg} / \mathrm{kg}$ & $1-3 \mathrm{mcg} / \mathrm{kg} / \mathrm{h}$ \\
\hline *A indicação de infusão contínua de lidocaína é apenas para cães. As doses e associações devem ser ajustadas de \\
acordo com o quadro clínico e o grau de analgesia esperado para cada paciente. Adaptado de Quandt e Lee (2015), \\
Mathews et al. (2014) e McKenzi (2008).
\end{tabular}

\subsubsection{Adjuvantes analgésicos}

Diversos medicamentos que não se enquadram nas classes farmacológicas dos analgésicos tradicionais têm sido recentemente incorporados em protocolos para o tratamento da dor. Estes fármacos não possuem efeitos analgésicos desejáveis quando administrados isoladamente, por isso são frequentemente empregados em combinações com opióides, AINEs e anestésicos locais (MATHEWS et al., 2014).

A cetamina é um fármaco utilizado na prática clínica veterinária há décadas para anestesia dissociativa ou em associação com outros agentes para produzir contenção química (LAMONT, 2008b). Em doses subanestésicas é capaz de promover analgesia sem a depressão anestésica ou sedação profunda que se observa com a administração de doses mais elevadas (McKENZI, 2008). A ativação do receptor NMDA é um ponto crítico no processo de sinalização nociceptiva (McKUNE et al., 2015) e, como resultado da inibição deste receptor, a cetamina atua principalmente modulando a sensibilização central e exercendo um efeito anti-hiperalgésico. Clinicamente, sua aplicação se dá como componente analgésico no manejo multimodal da dor em cirurgias maiores, em pacientes traumatizados ou como parte do tratamento para dessensibilização em pacientes com dor crônica (MATHEWS et al., 2014).

Os antidepressivos tricíclicos, tais como a amitriptilina e a imipramina, são uma classe de medicamentos amplamente utilizada para o tratamento da dor neuropática em humanos (BERRY, 2015). Estes fármacos atuam bloqueando a recaptação de catecolaminas, o que estimula a transmissão adrenérgica (MATHEWS et al., 2014). A amitriptilina é um antidepressivo tricíclico que possui diversos mecanismos antinociceptivos benéficos, quais sejam a inibição da receptação de serotonina e norepinefrina e antagonismo sobre o receptor NMDA. É comumente usada em combinação com outros analgésicos para o tratamento da dor crônica, porém requer uma avaliação detalhada do paciente antes de seu uso em função de suas numerosas interações medicamentosas com outros compostos, além de eventuais efeitos adversos anticolinérgicos e sedação (BECKMAN, 2013).

A amantadina é um antiviral e antiparkinsoniano que possui ação inibidora da receptação de monoaminas e antagonista NMDA. Pode ser utilizada em associação com outros analgésicos tradicionais para o tratamento da dor crônica e da sensibilização central (BECKMAN, 2013). Altas doses deste fármaco são pró-convulsivantes e, em função de sua excreção ocorrer por via renal, seu uso deve ser ponderado em pacientes com disfunção renal (MATHEWS et al., 2014).

A gabapentina é um anticonvulsivante capaz de produzir analgesia por inibir a liberação de neurotransimissores como o glutamato e a substância $\mathrm{P}$ e antagonizar os receptores NMDA no corno dorsal da medula espinhal (BERRY, 2015). Além disso, é capaz de ativar a via descendente inibitória da dor por induzir a liberação de norepinefrina, que, consequentemente, promove 
analgesia em função da estimulação dos receptores alfa2-adrenérgicos espinhais (MATHEWS et al., 2014).

O maropitant é um anti-emético de ação central que atua bloqueando os receptores da neurocinina-1 (NK1) no SNC. Este receptor e seu ligante endógeno, a substância P, estão envolvidos na via aferente do processamento nociceptivo. Ensaios experimentais demonstraram que os antagonistas do receptor NK1 induzem analgesia em cobaias. Em cães, sabe-se que a administração intravenosa de maropitant reduz o requerimento de isoflurano na anestesia geral, porém as evidências ainda são escassas e maiores estudos ainda são necessários para demonstrar seu potencial analgésico em condições clínicas (BERRY, 2015; MATHEWS et al., 2014).

\subsubsection{Abordagens não farmacológicas da dor perioperatória}

Abordagens não farmacológicas no manejo da dor continuam a ser a base para todas as outras terapêuticas, tais como uma técnica operatória meticulosa - limitando a lesão tecidual e a nocicepção pós-operatória - e outros cuidados, tais como a manutenção de higienização adequada, posicionamento adequado dos animais e suavizar as superfícies onde encontram-se os pacientes imobilizados durante a hospitalização (HANSEN, 2008), massagem medicinal e imobilização de membros ou articulações (MATHEWS et al., 2014), além de minimizar o estresse durante as manipulações e garantir um suporte nutricional apropriado para promover a cura e a recuperação (BERRY, 2015).

A acupuntura é uma modalidade de estímulos mecânicos que tem apresentado um importante papel no manejo de condições dolorosas em pequenos mamíferos (ALLWEILER, 2016). Dentre as técnicas não farmacológicas com efeitos analgésicos reconhecidos estão a acupuntura manual e a eletroacupuntura, que ativam o sistema somatossensorial para estimular uma resposta supressiva à dor (FREITAS et al., 2016).

Outras modalidades baseadas em princípios físicos são a crioterapia, laserterapia, estimulação eletrica nervosa transcutânea (TENS, do inglês transcutaneous electrical nerve stimulation), termoterapia por calor, ultrassom terapêutico e terapia eletromagnética pulsada (MATHEWS et al., 2014).

\section{Conclusão}

O advento de novos fármacos, a analgesia preemptiva e as técnicas de analgesia multimodal, além das técnicas não farmacológicas, trouxeram grandes avanços para o tratamento da dor em pequenos animais, porém a efetividade da terapêutica analgésica proposta depende do conhecimento dos diversos aspectos fisiofarmacológicos e neuroendócrinos envolvidos em todos os processos da nocicepção e do reconhecimento adequado da dor pelo médico veterinário, permitindo a eleição e associação de fármacos apropriados para o tipo de dor ocorrente, sua magnitude e às particularidades de cada paciente.

\section{Referências}

ALLWEILLER, S. I. How to improve anesthesia and analgesia in small mammals. Vet. Clin. Exot. Anim., v. 19, p. 361-377, 2016.

ANTUNES, M. I. P. P.; MORENO, K.; GRUMADAS, C. E. S. Avaliação e manejo da dor em cães e gatos com câncer - Revisão. Arq. Ciênc. Vet. Zool. Unipar, v. 11, n. 2, p. 113-119, 2008.

BECKMAN, B. Anesthesia and pain management for small animals. Vet. Clin. Small. Anim., v. 43, p. 669-688, 2013. 
BELMONTE, E. A.; NUNES, N.; THIESEN, R.; LOPES, P. C. F.; COSTA, P. F.; BARBOSA, V. F.; MORO, J. V.; BATISTA, P. A. C. S.; BORGES, P. A. Infusão contínua de morfina ou fentanil, associados à lidocaína e cetamina em cães anestesiados com isoflurano. Arq. Bras. Med. Vet. Zootec., v. 65, n. 4, p. 1075-1083, 2013.

BERRY, S. H. Analgesia in the perioperative period. Vet. Clin. Small Anim., v. 45, p. 1013-1027, 2015.

BROOM, D. M.; MOLENTO, C. F. M. Bem-estar animal: Conceito e questões relacionadas Revisão. Archives of Veterinary Science, v. 9, n. 2, p. 1-11, 2004.

CASTRO LOPEZ, J. M. Fisiopatologia da dor. Lisboa: Permanyer Portugal, 2003. 36p.

DYSON, D. H. Analgesia and chemical restraint for the emergent veterinary patient. Vet. Clin. Small Anim., v. 38, p. 1329-1352, 2008.

ELVIR-LAZO, O. L.; WHITE, P. F. Postoperative pain management after ambulatory surgery: Role of multimodal analgesia. Anesthesiology Clin., v. 28, p. 217-224, 2010.

FANTONI, D.; MARTINS, A. Analgesia para cirurgia geral. In: FANTONI, D. Tratamento da dor na clínica de pequenos animais. Rio de Janeiro: Elsevier, 2011. p. 261-276.

FLECKNELL, P. Analgesia from a veterinary perspective. British Journal of Anesthesia, v. 101, n. 1, p. 121-124, 2008.

FREITAS, A. T. A. G.; LEMONICA, L.; FAVERI, J.; PEREIRA, S.; HENAO, M. D. B. Preemptive analgesia with acupuncture monitored by c-Fos expression in rats. J. Acupunct. Meridian Stud., v. 9, n. 1, p. 16-21, 2016.

GARCIA, J. B. S.; ISSY, A. M.; SAKATA, R. K. Analgesia preemptiva. Rev. Bras. Anestesiol., v. 51, n. 5, p. 448-463, 2001.

GOZANNI, J. L. Fisiopatologia da dor. In: CAVALCANTI, I. L.; MADDALENA, M. L. Dor. Rio de Janeiro: Sociedade de Anestesiologia do Estado do Rio de Janeiro, 2003. 299p.

GRAPE, S.; TRAMER, M. R. Do we need preemptive analgesia for the treatment of postoperative pain? Best practice \& research clinical anesthesiology, v. 21, n. 1, p. 51-63, 2007.

GRUBB, T. Where do we go from here? Future treatment strategies for chronic pain. Topics in companion animal medicine, v. 25, n. 1, p. 59-63, 2010.

HANSEN, B. Analgesia for the critically ill dog or cat: An update. Vet. Clin. Small Anim., v. 38, p. 1353-1362, 2008.

HELLYER, P.; RODAN, I.; BRUNT, J.; DOWNING, R.; HAGEDORN, J. E.; ROBERTSON, S. A. Pain management guidelines for dogs \& cats. J. Am. Anim. Hosp. Assoc., v. 43, p. 235-248, 2007.

KLAUMANN, P. R.; WOUK, A. F. P. F.; SILlAS, T. Patofisiologia da dor. Archives of Veterinary Science, v. 13, n. 1, p. 1-12, 2008. 
LAMONT, L. A. Adjunctive analgesic therapy in veterinary medicine. Vet. Clin. Small Anim., v. 38, p. 1187-1203, 2008b.

LAMONT, L. A. Multimodal pain management in veterinary medicine: The physiologic basis of pharmacologic therapies. Vet. Clin. Small Anim., v. 38, p.1173-1186, 2008a.

LE BARS, D.; GOZARIU, M.; CADDEN, S. W. Animal models of nociception. Pharmacol. Rev., v. 53, p. 597-652, 2001.

LEE, S. K.; LEE, J. W.; CHOY, W. S. Is multimodal analgesia as effective as postoperative patient-controlled analgesia following upper extremity surgery? Orthpaedics \& Traumatology: Surgery \& Research, v. 99, p. 895-901, 2013.

LIMA SILVA, F.; ALVES DA SILVA, C. R.; COSTA, A. P. R. Terapêutica da dor na cirurgia de cães e gatos: Revisão. Veterinária em Foco, v. 9, n. 1, p. 57-75, 2011.

MACINTYRE, P. E.; SCOTT, D. A.; SCHUG, S. A.; VISSER, E. J.; WALKER, S. M. Acute pain management: Scientific evidence. 3rd edition. Melbourne: Australian and New Zealand College of Anesthetists, 2010. 485p.

MATHEWS, K.; KRONEN, P. W.; LASCELLES, D.; NOLAN, A.; ROBERTSON, S.; STEAGALL, P.; WRIGHT, B.; YAMASHITA, K. Guidelines for recognition, assessment and treatment of pain. Journal of Small Animal Practice, v. 55, p. E10-E68, 2014.

McKENZI, G. Total Intravenous Anesthesia - TIVA. Iranian Journal of Veterinary Surgery, supplement for the 2nd ISVS \& 7th ISVSAR, p. 108-117, 2008.

McKUnE, M. C.; MURRELl, J. C.; NOLAN, A. M.; WhITE, K. L.; WRIGHT, B. D. Nociception and pain. In: GRIMM, K. A.; LAMONT, L. A.; TRANQUILLI, W. J. GREENE, S. A.; ROBERTSON, S. A. Veterinary anesthesia and analgesia - The fifth edition of Lumb and Jones. Hoboken: Wiley-Blackwell, 2015. p. 584-616.

NAIDU, R. K.; PHAM, T. M. Pain management. In: SIKKA, P. K.; BEAMAN, S. T.; STREET, J. A. Basic Clinical Anesthesia. New York: Springer, 2015. p. 265-296.

PERKOWSKI, S. Pain and sedation assessment. In: SILVERSTEIN, D. C.; HOPPER, K. Small Animal Critical Care Medicine. 2nd edition. St. Louis: Elsevier Saunders, 2015. p. 749-753.

QUANDT, J.; LEE, J. A. Analgesia and constant rate infusions. Small Animal Critical Care Medicine. 2nd edition. St. Louis: Elsevier Saunders, 2015. p. 766-772.

TEIXEIRA, M. J. Fisiopatologia da nocicepção e da supressão da dor. JBA, v. 1, n. 4, p. 329-334, 2001.

VALLEJO, M. C.; PHELPS, M. L.; NEERA, S.; ROMEO, R. C.; FALK, J. S.; JOHNSON, R. R.; KEENAN, D. M.; BONAVENTURA, M. A.; EDINGTON. H. D. Preemptive analgesia with bupivacaine for segmental mastectomy. Regional anasthesia and pain medicine, v. 31, n. 3, p. 227-232, 2006. 
WHITTEM, T.; BETHS, T.; BAUQUIER, S. General pharmacology of anesthetic and analgesic drugs. In: GRIMM, K. A.; LAMONT, L. A.; TRANQUILLI, W. J. GREENE, S. A.; ROBERTSON, S. A. Veterinary anesthesia and analgesia - The fifth edition of Lumb and Jones. Hoboken: Wiley-Blackwell, 2015. p. 147-174.

YOUNG, A.; BUVANENDRAN, A. Recent advances in multimodal analgesia. Anesthesiology Clin., v. 30, p. 91-100, 2012. 